\title{
Systematic Review on Prevalence for Autism Spectrum Disorder with Respect to Gender and Socio-Economic Status
}

\author{
Bappaditya Adak ${ }^{1}$ and Santoshi Halder ${ }^{2 *}$ \\ ${ }^{1}$ University of Calcutta, India \\ ${ }^{2}$ Department of Education, University of Calcutta, India
}

\begin{abstract}
The prevalence of Autism Spectrum disorder has been increased rapidly worldwide in last few years. However most of the estimation comes from developed regions of western countries. There are no reliable and consistent data from non-western or non-affluent countries.

Aim: The primary aim of this systematic review was to synthesise the results of wide range of epidemiological studies to estimate prevalence of ASD with respect to gender and socio-economic status (SES). Secondarily, available studies were analyzed with identified themes for assessing the trend of these studies.

Methods: Based on pre-defined inclusion and exclusion criteria epidemiological reports were identified by internet search and recent relevant papers were included (2005-2015).

Results: 27 eligible studies were identified for review of which 22 estimated Autism spectrum Disorder (ASD) or Pervasive developmental disorder (PDD) and 4 concentrated on typical Autism. Most of the studies used special educational and mainstream school records $(\mathrm{N}=11)$ for data extraction. Overall mean age of study samples ranged between ages 2-17 years. International classification of disabilities (ICD)-9 and 10 criteria as well as Diagnostic Statistical Manual (DSM)-III and IV criteria were retained for diagnostic assessment. The average prevalence of these twenty seven studies was 91.92 per 10,000 populations. The reported prevalence of ASD varied substantially by country and continent, use of methodology, assessment tools, gender, geographic region and Socioeconomic status (SES).

Conclusion: Recent studies provided higher estimation and prevalence rate in developed or much affluent countries as well as urban areas. Also Parental high SES was found positively associated with prevalence of ASD. Analyses suggest more strong instruments and awareness is needed. Also more population based investigations is needed in rural as well as developing countries for revealing clear picture of this disability.
\end{abstract}

Keywords: Autism spectrum disorder; Prevalence; Systematic review; Gender; Socio-economic status

\section{Introduction}

In last two decades the number of diagnoses of Autism Spectrum disorder (ASD) has been increased drastically throughout the world $[1,2]$.The diagnosis rate of ASD increases 4.5 per 10,000 children's in 1943 [3] to 110 per 10,000 in 2009 [4] in western countries. Prevalence studies suggest that most of the estimation comes from regions of Europe and United States, where standardised services are available for diagnosis. According to recent report Centers for Disease Control and Prevention [5] identified 1 per 68 children's ( 1 in 42 boys and 1 in 189 girls) have ASD in United States. In last two decades preliminary efforts have been taken in non-western countries to estimate prevalence of ASD. As an example presently more than 10 million children are (aged between 9 to 10 years) effected by ASD in India. In some other Asian countries the prevalence rate increases accordingly, Japanese has 21.1 per 10,000 to 181 per 10,000, South Korea reported 264 per 10,000 in 2011 [6], and China has 10.3 per 10,000 children's [7]. But this estimates show a great amount of inconsistency while researchers considered that the numbers are increasing truly.

Though researchers identified drastically increase of ASD universally, but there remains a great amount of inconsistency in the prevalence rate in developed and developing countries. Literature shows that the dramatically increase rate of ASD risen in developed countries most of the time [8]. There was a great imbalance in delivery of services around the world. Specifically Low Resource Community and Countries (LRCC) faced more problems than high resource countries. Therefore low or middle income regions of developed countries have not identified so much increase of ASD rate than high resource community and countries. According to a recent estimation epidemiological studies identified around $87 \%$ of the ASD cases in Europe, Japan and North America, while only $10 \%$ of the worlds children's lives in these countries [9]. Due to lack of knowledge, awareness and socio-economic disparities majority of individuals with ASD living in low and middle income countries and were not identified properly. Therefore these unidentified peoples were not represented in world prevalence studies.

Because of this inconsistent estimation recently researchers descended on debate over whether this is real increase or not. Several explanation have been proposed by the researchers for this high estimation including modified diagnostic criteria, improved diagnostic instruments, the broader definition of ASD, uses of different research

*Corresponding author: Santoshi Halder, Associate Professor, Department of Education, University of Calcutta, India, Tel: 8961044413/9051010052; E-mail: santoshi_halder@yahoo.com; shedu@caluniv.ac.in

Received February 02, 2017; Accepted February 06, 2017; Published February 13, 2017

Citation: Adak B, Halder S (2017) Systematic Review on Prevalence for Autism Spectrum Disorder with Respect to Gender and Socio-Economic Status. J Ment Disord Treat 3: 133. doi:10.4172/2471-271X.1000133

Copyright: (๑) 2017 Adak B, et al. This is an open-access article distributed under the terms of the Creative Commons Attribution License, which permits unrestricted use, distribution, and reproduction in any medium, provided the original author and source are credited. 
methodologies, cultural differences and greater awareness and recognition of ASD.

\section{Methodological improvement}

Researchers give strong explanation that the methodology used by several studies throughout the years has been changed according to the needs of the time. After precise the case definition researcher should made effort to find out sampling criteria. Prevalence estimation varied with sampling methodology and survey designed including already diagnosed large clinical samples to non-clinical undiagnosed populations or misdiagnosed and milder forms of ASD phenotype. Depending on the study context researcher may include random or non-random samples with high representativeness to target populations to estimate prevalence of ASD. Most of the time non-random samples have common limitations that undiagnosed and non-documented cases were not included in national registry or education, health or other service provider's database, therefore many remains unrecognized [10]. Presently prevalence estimation are derived from a number of ways through non-random sampling such as national registries, health and special education registers, service providers records, retrospective accounts and telephone interviews. Researchers also used random sampling methodology to identify cases through multi-source recordsreview surveillance approach, multiphase total population surveillance approach and whole area surveys. No doubt research methodologies can impact on result of prevalence estimation. But these sampling methodologies have some limitations. As an example national registries can be helpful for countries with single health care system and small geographic area [11]. Also special educational information's are only used for service use purposes. Therefore only those children's were counted who meet the service criteria and others (home-schooled) remain underestimated in prevalence categories. Similarly health records are not sufficient due to lack of quality diagnosis. Therefore it is obvious that ASD rates may differ in terms of methodology used for data extraction.

\section{Improved diagnostic criteria}

The ever changing diagnostic criteria and definition of subcategories of ASD have been considered the common reasons of increased prevalence of ASD [12,13]. In 1980, Diagnostic and Statistical Manual of mental disorders ( $3^{\text {rd }}$ edition) first included ASD and offer formal diagnostic criteria [14]. After that APA expanded and modified the diagnostic criteria accordingly with [15]. Through this updated diagnostic edition DSM changes the classification of symptom recognition and categorized ASD. Therefore periodic revision of diagnostic criteria and used of different criteria when estimate ASD prevalence may increased the possibility of misinterpreted increase. Specifically after the publication of DSM-5 [15] the diagnostic criteria have been changed totally and merged five categories in one umbrella term ASD; and expansion the age on set criteria into childhood ASD. This changes no doubt impact the existing prevalence of ASD. Also some researchers used International classification of diseases (ICD) series as parallel diagnostic criteria of ASD; which also increases the complexity of understanding of increases rate of ASD because DSM-III (R) criteria are different from ICD-10.

\section{Improved diagnostic instruments}

In conjunction with modification of diagnostic criteria of ASD assessment tools have been improved over the years. In recent years based on developmental history of child and direct observation clinicians developed several standardised systematic diagnostic instruments. These instruments improved the detection process of ASD and measured the degree of impairment properly. Moreover researchers give emphasis on collection of systematic developmental data of children's as complex diagnostic assessment. Diagnostic tools such as Autism Diagnostic Interview revised [16], Autism Diagnostic Observational Schedule, and Diagnostic Interview for Social and Communication Disorder (DISCO) are commonly used worldwide by professionals with good training. The changing assessment tools can contribute to marked increase of cases in different studies [17]. But in low resource country like India researcher compel to use western countries diagnostic instruments without any cross cultural verification and revalidation. These tools are costly, lengthy, and need professional training to administer. Also these research tools were not extended due to lack of free access services. Researchers stated that due to inequality and convenience sampling approach most of the ASD research focused on high economic group for the development of assessment tools [18]. So there remains some inconsistency in ASD prevalence in low and middle income countries like India.

\section{Socio-economic advancement}

Cultural beliefs, norms and expectations greatly influenced the identified features of ASD [13]. Also socio-economic condition of parents affects the diagnosis and prevalence of ASD. Because parent's with a high income and high education are much more aware of the problems and are close to important services. Therefore in comparison to other countries the prevalence of ASD is much higher in developed countries. This socio-economic inequalities build our knowledge biased and incomplete because most of the researches concentrate on high income setting which might miss other perspectives of ASD including cultural back ground, sociological impact and natural history of ASD [18]. Also low recourse countries cannot avail the existing services due to cost and feasibility. More over research funding is limited in India for improving diagnostic tools and translate popular assessment instruments. Therefore inaccessibility impacts the world population of ASD increasingly.

In the same time researcher found a male dominance of the disorder from the earlier time. But presently there is no reliable statistics on prevalence of ASD in many countries including India. Thus present study attempt to review the trend of prevalence of ASD in respect to SES and gender for the last 15 years worldwide including developed and developing countries. The primary objective of this systematic review is to provide a clear picture of the methodology used by epidemiological studies and their results regarding prevalence of ASD worldwide. Meanwhile the limitation is that present review included very few available studies, therefore extensive coverage is not found (Table 1).

\section{Outcome of the results}

As per the inclusion and exclusion criteria overall 26 studies were included in the present systematic review. Most of the studies have been published in last 10 years and cover 18 countries (Table 1). The included studies were analysed with the following themes that is trend with respect to country or continent, geographical origin of the study that is rural or urban, gender, SES, the tools used for assessing prevalence, methodology adopted for exploring the prevalence and limitation of the studies conducted. Most of the studies focusing on 2-17 years old children's as participant of the study. The population size varied with the reviewed studies ranged from 500 to 1.32 billion. Also $60 \%(\mathrm{~N}=16)$ studies uses the term Autism Spectrum Disorder (ASD), $10 \%(\mathrm{~N}=3)$ studies uses Autism Spectrum Condition (ASC), 15\% ( $\mathrm{N}=4)$ 
Citation: Adak B, Halder S (2017) Systematic Review on Prevalence for Autism Spectrum Disorder with Respect to Gender and Socio-Economic Status. J Ment Disord Treat 3: 133. doi:10.4172/2471-271X.1000133

Page 3 of 9

\begin{tabular}{|c|c|}
\hline Search strategies & Description \\
\hline \multicolumn{2}{|l|}{ 1. Inclusion criteria } \\
\hline 1.1 Year limit of publications & Studies published from 2015 to 2005 only included \\
\hline 1.2. Nature of ASD & $\begin{array}{l}\text { According to DSM-IV and DSM-5 all the ASD categories were included (autistic disorder, Aspergers syndrome, childhood } \\
\text { disintegrative disorder, Rett's syndrome and Pervasive Developmental Disorder-Not Otherwise Specified). }\end{array}$ \\
\hline 1.3 Nature of study & $\begin{array}{l}\text { Only full published studies were included published in peer reviewed English language journals is available in University of } \\
\text { Calcutta access. }\end{array}$ \\
\hline 1.4 Satisfactory sample size & Only those studies were included who did the prevalence with the sample size of more than 50 . \\
\hline 2. Exclusion criteria & $\begin{array}{l}\text { Other research articles including case studies, surveys on neuro developmental disorders, and studies estimating co- } \\
\text { morbidities with PDD were also excluded from current review. }\end{array}$ \\
\hline \multicolumn{2}{|l|}{ 3. Search strategies } \\
\hline 3.1 search engine & Internet search strategy was employed to identify the epidemiological reports. \\
\hline 3.2. Key words & $\begin{array}{l}\text { Epidemiology of autism spectrum disorder (ASD), screening of ASD, prevalence of ASD, diagnosis of ASD, present estimation } \\
\text { of ASD, gender difference in prevalence of ASD, male dominance of ASD, present rate of ASD, socio-economic status of } \\
\text { parents, parent education and occupation. }\end{array}$ \\
\hline 4. Focus area & $\begin{array}{l}\text { Only those studies were included which covered country or continent name, nature of population and sample, diagnostic } \\
\text { criteria used for case ascertainment, male female ratio, and prevalence estimation }\end{array}$ \\
\hline
\end{tabular}

studies uses Pervasive developmental Disorder (PDD) and 15\% (N=4) studies concentrate on pure Autism. For the better understanding of the occurrence of ASD in general population a considerable literature has been developed, which reported that incidence of ASD increasing reportedly. Therefore present systematic review chronologically synchronizes the samples.

\section{Country/continent}

Present systematic review conducted on study of 18 countries under 5 major continent namely (1) Europe including Netherland, England, Iceland, Sweden, Spain, Portugal, and UK (N=7), (2) North America including Canada and USA $(\mathrm{N}=2)$, (3) South America including Venezuela, (4) Asia including China, South Korea, Thailand, Israel, Iran and India $(\mathrm{N}=6)$ and Australia including a single study $(\mathrm{N}=1)$. Therefore present review covers only main five continent of the world and other two continents namely Africa and Antarctica were not presented due to lack of studies and inclusion and exclusion criteria not met for these studies. Present study covers $26 \%$ of the Asian studies $(\mathrm{N}=7), 28 \%$ of the American studies $(\mathrm{N}=8)$ and $41 \%$ Europe continent studies $(\mathrm{N}=11)$ and $3 \%$ Australian studies $(\mathrm{N}=1)$. Review also shows that $63 \%$ studies were conducted in urban locality $(\mathrm{N}=16$, studies like Sun et al.; Lowe et al.; Taylor et al.) and 33\% studies were conducted in both rural and urban locality combined $(\mathrm{N}=9$, studies such as Saemundsen et al. [19], Ping et al. [20]; Idring et al. [21]). Only one study in Chiang Mai held on rural population [22].

According to Table 1 in Asian countries South Korea had maximum rate of prevalence (264 per 10,000, Kim et al. [6]). It was the first population based prevalence study in Korea as well as in Asia in recent years. Therefore the significance of this study was very high because researchers included both general and high probability group of ASD from entire elementary schools of South Korea. Also this study estimated prevalence of ASD in different settings with phenotypic variability. In the same time it includes a big amount of children's for screening (that is 55266 children's) from both urban and rural areas. In European countries Netherland had greater increase of ASD among 4-16 years old children's (229 per 10,000; Roelfsema et al. [23]). This study involved three information technology region of country namely Eindhoven, Haarlem and Utrecht to examine whether the regional variations are associated with prevalence of ASD by systemizing theory. This study has great impact on future research of ASD, because most of the peoples believed that ASD is more prevalent in UK populations as well as US. But this study proves that ASD is universal. Also raised a question that whether ASD is more prevalent in technology and industrial area than other regions of country? Continent wise analysis shows that the trend of higher prevalence was more prevalent in urban geographical areas as researchers focused mainly in urban areas $[4,6,17,23]$. Systematic table shows that developing countries explored both rural and urban area scenario with the help of existing data [24].

\section{Methodology}

The case identification and sample collection procedure of studies were presented here (Table 1). Every investigation applied their own strategy to identify the cases from general and health based data. Most of the studies used multistage approach to screened target populations. Out of the methodologies used worldwide present systematic review found total four sample sources by this investigations including, a) $25 \%$ followed general population based sampling technique $(\mathrm{N}=6$; as a example study of Kim et al. [6]; Samadi et al. [24]), b) 10\% studies followed medical and health records, $(\mathrm{N}=3$; as a example study of Ping et al.; Taylor et al. [25]; Montiel-Nova et al. [26]), c) 40\% studies followed special educational and mainstream schools records, $(\mathrm{N}=11$; as a example study of Roelfsema et al. [23]; Aguilera et al. [27]; Sun et al. [7]; Lowe et al. [28]), and d) $25 \%$ studies followed national birth register or birth cohort ( $\mathrm{N}=7$; as a example study of King et al. [29]).

According to present review most of the studies used special educational and mainstream school records to estimate prevalence of ASD in a particular region of country. This technique can include a high percentage of representative random samples from special education centre; as well as screen new cases from mainstream children's. As an example Roelfsema et al. [23] include three information and technology based areas samples (Eindhoven, Haarlem and Utrecht) from mainstream school aged children's through formal diagnosis and identified a great amount of children's successfully. According to researchers schools records can cover broad geographical areas as well as cross section of rural and urban areas. Also this special educational records help researchers to identify children's with ASD easily because only special education centres allow disabled children's to pursue their education.

Present review show that most of the developed countries (as an example study of Roelfsema et al. [23]; Aguilera et al. [27]; Sun et al. [7]) as well as developing countries (as an example study of Sharda et al. [24]; Surinkaew et al. [22]) used special educational and mainstream enrolments data for identification of cases in estimating prevalence of ASD. 
Citation: Adak B, Halder S (2017) Systematic Review on Prevalence for Autism Spectrum Disorder with Respect to Gender and Socio-Economic Status. J Ment Disord Treat 3: 133. doi:10.4172/2471-271X.1000133

\section{Age of the sample}

In present review some studies mentioned children's age groups, while some measure children's age specific estimation as well. Overall 0-37 years old age peoples were presented by these studies. According to present review (Table 2) 11\% studies included preschool children's that is $0-5$ years old children's ( $\mathrm{N}=3$; as an example studies of Ping et al. [20]); 51\% studies used primary school age children's that is 6-12 years old children's ( $\mathrm{N}=14$, as an example studies of Saemundsen et al. [19]; Taylor et al. [25]; King et al. [29]; Maenner et al. [30]); 25\% studies include pre to secondary school age long age group that is $0-18$ years old ( $\mathrm{N}=7$, studies like; William et al. [13]); and $11 \%$ studies include

\begin{tabular}{|c|c|c|c|c|c|c|c|c|c|c|c|c|c|c|c|c|}
\hline $\begin{array}{l}\text { Sl. } \\
\text { No }\end{array}$ & Authors & Year & Journal & Country & Continent & Region & $\begin{array}{l}\text { Area } \\
\text { (Rural/ } \\
\text { Urban) }\end{array}$ & $\begin{array}{l}\text { Category } \\
\text { of ASD }\end{array}$ & Population & Age & $\begin{array}{l}\text { Number } \\
\text { affected }\end{array}$ & $\begin{array}{l}\text { Diagnostic } \\
\text { Criteria }\end{array}$ & $\begin{array}{l}\text { Diagnostic } \\
\text { tools }\end{array}$ & $\begin{array}{l}\text { Gender } \\
\text { ratio }\end{array}$ & $\begin{array}{l}\text { Prevalence } \\
\text { per } 10,000\end{array}$ & Limitation \\
\hline 1 & Raz et al. & 2015 & $\begin{array}{l}\text { Journal of } \\
\text { developmental } \\
\text { disorder }\end{array}$ & Israel & Asia & & Mixed & ASD & 2431,649 & $8-18$ & 9109 & DSM-IV-TR & $\begin{array}{l}\text { ADI, } \\
\text { CARS, } \\
\text { ADOS, }\end{array}$ & 4.4:5.6 & 50 & $\begin{array}{l}\text { The population was } \\
\text { not properly defined }\end{array}$ \\
\hline 2 & $\begin{array}{l}\text { Saemundsen } \\
\text { et al. }\end{array}$ & 2015 & BMJ open & Iceland & Europe & Reykjavik & Mixed & ASD & 22,229 & $0-8$ & 267 & $\begin{array}{l}\text { DSM-IV } \\
\text { ICD-10 }\end{array}$ & $\begin{array}{l}\text { ADOS, } \\
\text { ADI-R }\end{array}$ & $1.8: 1$ & 120 & $\begin{array}{l}\text { Second phase } \\
\text { clinical screening } \\
\text { was not performed }\end{array}$ \\
\hline 3 & Sun et al. & 2015 & $\begin{array}{l}\text { Autism } \\
\text { Research }\end{array}$ & China & Asia & Beijing & Urban & ASC & 714 & $6-11$ & 8.5 & $\begin{array}{l}\text { DSM-IV, } \\
\text { ICD-10 }\end{array}$ & $\begin{array}{l}\text { ADOS, } \\
\text { CAST }\end{array}$ & $4: 1$ & 119 & $\begin{array}{l}\text { Small sample size, } \\
\text { low score groups } \\
\text { were not reassessed } \\
\text { and instruments } \\
\text { were not revalidated }\end{array}$ \\
\hline 4 & Lowe et al. & 2014 & $\begin{array}{l}\text { School of } \\
\text { public policy } \\
\text { Research } \\
\text { papers }\end{array}$ & Canada & America & Alberta & Urban & ASD & 160,904 & $4-18$ & 1,711 & DSM-IV & & $5.2: 1$ & 94 & $\begin{array}{l}\text { Same standard of } \\
\text { diagnosis were not } \\
\text { used by clinicians }\end{array}$ \\
\hline 5 & Ping et al. & 2014 & $\begin{array}{l}\text { Biomedical } \\
\text { Environment } \\
\text { study }\end{array}$ & China & Asia & Tianjin & Mixed & ASD & 8000 & $\begin{array}{l}1.5- \\
2.5\end{array}$ & 367 & DSM-IV & CHAT & $4: 1$ & 27.5 & $\begin{array}{l}\text { study was over } \\
\text { representative of } \\
\text { urban children }\end{array}$ \\
\hline 6 & Taylor et al. & 2013 & BMJ open & UK & Europe & & Urban & Autism & $\begin{array}{l}132143 \\
124135\end{array}$ & $2-8$ & $\begin{array}{l}515 \\
101\end{array}$ & DSM-IV & & & 38 & $\begin{array}{l}\text { there is a large } \\
\text { difference in the } \\
\text { percentage of } \\
\text { children diagnosed } \\
\text { as autistic in the two } \\
\text { countries }\end{array}$ \\
\hline 7 & $\begin{array}{l}\text { Blumberg } \\
\text { et al. }\end{array}$ & 2013 & $\begin{array}{l}\text { National } \\
\text { health } \\
\text { Statistics } \\
\text { Report }\end{array}$ & $\begin{array}{l}\text { United } \\
\text { States }\end{array}$ & America & & Urban & ASD & 95,677 & $6-17$ & & $\begin{array}{l}\text { DSM-IV } \\
\text { ICD-10 }\end{array}$ & $\begin{array}{l}\text { stratum- } \\
\text { adjusted } \\
\text { Cochran- } \\
\text { Mantel- } \\
\text { Haenszel } \\
\text { tests }\end{array}$ & $4: 1$ & 200 & $\begin{array}{l}\text { validity of parent } \\
\text { reports may be } \\
\text { uncertain }\end{array}$ \\
\hline 8 & Idring et al. & 2012 & Plos one & Sweden & Europe & Stockholm & Mixed & ASD & 444,154 & $0-17$ & 5,100 & $\begin{array}{l}\text { DSM-IV-TR } \\
\text { ICD-10 }\end{array}$ & & 2.6:1 & 115 & $\begin{array}{l}\text { Case validation was } \\
\text { based on case- } \\
\text { note review rather } \\
\text { than direct clinical } \\
\text { assessment. }\end{array}$ \\
\hline 9 & $\begin{array}{l}\text { Roelfsema } \\
\text { et al. }\end{array}$ & 2012 & \begin{tabular}{l|} 
Journal of \\
Autism and \\
Developmen- \\
tal Disorders
\end{tabular} & $\begin{array}{l}\text { Nether- } \\
\text { lands }\end{array}$ & Europe & $\begin{array}{l}\text { Eind- } \\
\text { hoven, } \\
\text { Haarlem, } \\
\text { Utrecht }\end{array}$ & Urban & ASC & $\begin{array}{l}269,504 \\
285,215 \\
288401\end{array}$ & $4-16$ & & $\begin{array}{l}\text { DSM-IV } \\
\text { ICD-10 }\end{array}$ & & & $\begin{array}{l}229,84 \\
57\end{array}$ & $\begin{array}{l}\text { Under-diagnosis } \\
\text { and over-diagnosis } \\
\text { may be the reason } \\
\text { of prevalence } \\
\text { difference between } \\
\text { three regions }\end{array}$ \\
\hline 10 & Sharda et al. & 2012 & $\begin{array}{l}\text { Nitte } \\
\text { University } \\
\text { Journal } \\
\text { of Health } \\
\text { Science }\end{array}$ & India & Asia & Karnataka & Mixed & Autism & 500 & $4-37$ & 74 & DSM-IV & & $2: 1$ & 12 & $\begin{array}{l}\text { Prevalence of } \\
\text { autism was done } \\
\text { based on clustering } \\
\text { sample rather } \\
\text { community based } \\
\text { samples. }\end{array}$ \\
\hline 11 & Samadi et al. & 2012 & SAGE & Iran & Asia & & Mixed & ASD & $\begin{array}{l}1.32 \\
\text { million }\end{array}$ & 5 & 3181 & DSM-IV & $\begin{array}{l}\text { ADI-R } \\
\text { SCQ }\end{array}$ & $4: 1$ & 6.62 & $\begin{array}{l}\text { Screening } \\
\text { instruments were } \\
\text { not revalidated }\end{array}$ \\
\hline 12 & Kim et al. & 2011 & $\begin{array}{l}\text { Am J } \\
\text { Psychiatry }\end{array}$ & $\begin{array}{l}\text { South } \\
\text { Korea }\end{array}$ & Asia & $\begin{array}{l}\text { Go Yang } \\
\text { city }\end{array}$ & Mixed & ASD & 55,266 & $7-12$ & 1214 & DSM-IV & $\begin{array}{l}\text { ASSQ, } \\
\text { ADOS }\end{array}$ & $5.1: 1$ & 264 & $\begin{array}{l}\text { risks of over and } \\
\text { underestimation }\end{array}$ \\
\hline 13 & Brugha et al. & 2011 & $\begin{array}{l}\text { Arch Gen } \\
\text { Psychiatry }\end{array}$ & England & Europe & London & Urban & ASD & 7461 & $16+$ & 618 & DSM-IV & $\begin{array}{l}\text { Autism } \\
\text { Spectrum } \\
\text { Quotient, } \\
\text { Autism } \\
\text { Diagnostic } \\
\text { Obser- } \\
\text { vation } \\
\text { Schedule }\end{array}$ & & 9.8 & $\begin{array}{l}\text { Lacked the } \\
\text { statistical power to } \\
\text { examine small but } \\
\text { possibly clinically } \\
\text { and etiologically } \\
\text { important } \\
\text { differences between } \\
\text { cohorts in rates of } \\
\text { ASD according to } \\
\text { age. }\end{array}$ \\
\hline
\end{tabular}


Citation: Adak B, Halder S (2017) Systematic Review on Prevalence for Autism Spectrum Disorder with Respect to Gender and Socio-Economic Status. J Ment Disord Treat 3: 133. doi:10.4172/2471-271X.1000133

Page 5 of 9

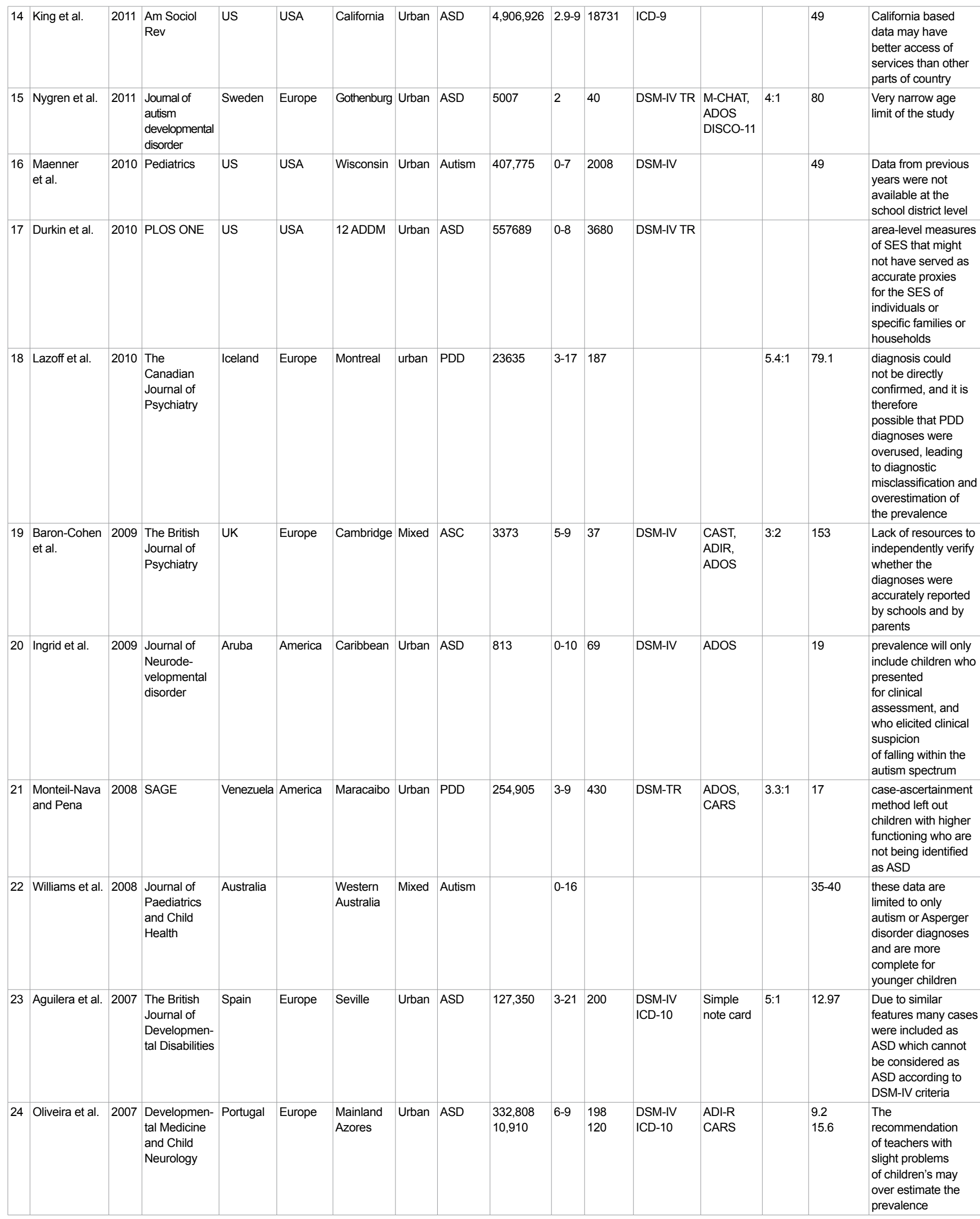




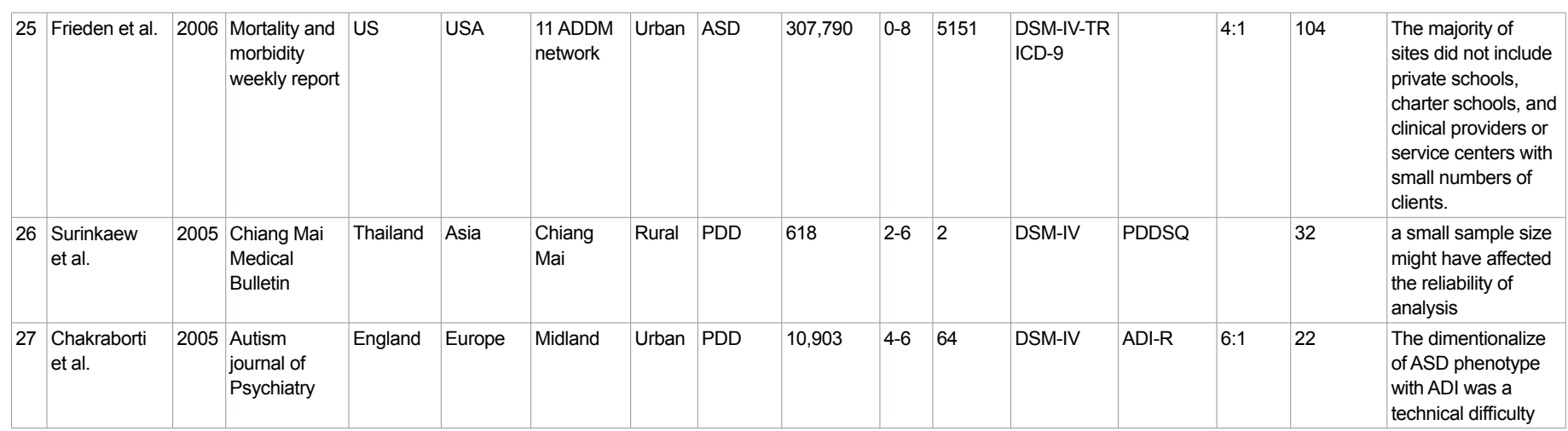

*12 ADDM=12 Automatic Database Diagnostic Monitor network,

*11 ADDM=11 Automatic Database Diagnostic Monitor network,

*ASD=Autism Spectrum Disorder, PDD=Pervasive Developmental Disorder, ASC=Autism spectrum Condition

${ }^{*}$ DSM-IV=Diagnostic and Statistical Manual of Mental Disorder, fourth edition.

*DSM-TR=Diagnostic and Statistical Manual of Mental Disorder, fourth edition (Text Revision).

*ICD-10=International Classification of Diseases, Tenth Revision

*ICD-9=International Classification of Diseases, Ninth Revision

"ADOS=Autism Diagnostic and Observation Schedule, ADI=Autism Diagnostic Interview, ADI-R=The Autism Diagnostic Interview-Revised, CARS=Childhood Autism Rating scale, CHAT=Checklist for Autism in Toddlers, MCHAT=Modified Checklist for Autism in toddlers, SCQ=Social Communication Questionnaire, ASSQ=Autism Spectrum Screening Questionnaire, PDDSQ=Pervasive Developmental Disorder Screening Questionnaire, DISCO=The Diagnostic Interview for Social and Communication Disorder.

Table 2: Socio economic background of families of these ASD children's.

adult age group ( $\mathrm{N}=3$, studies like Sharda et al. [24]; Brugha et al. [10] and Aguilera et al. [27]) (Table 1).

Present review showing the trend of age groups of samples and it is notified that maximum studies represented primary children's as samples of their prevalence studies. Therefore it is considered that researcher should involve pre-primary and primary group children's for prevalence estimation because the sign and symptoms are more prominent among these children's which help researchers to identify confidently. Monteil-Nava et al. [26] identified children's with ASD from general population with the mean age of 5.33. According to them the proportion of children's diagnosed with ASD decreased with age. According to Oliveira et al. [31] elementary education is free and compulsory in Portugal; and $100 \%$ children's attending schools in this age group. Therefore it was expected that all the children's with ASD should enrolled in three forms of education namely public, private and special education centres [31]. Interestingly developing countries found much older samples in their study such as Raz found 8 to 18 years old young people; Sharda et al. [24] found a wide age range with 4 to 37 years old people in their study.

\section{Assessment tools}

Table 2 show that prevalence studies were used variety of diagnostic and screening instruments ranging from detailed clinical inspection to use of standardized tests. Also DSM based definitions as well as ICD-9 and 10 criteria were retained to a large extent which reflects diagnostic assessment. According to Table 2, 37\% studies not mentioned any screening or assessment instruments in their report or not use any diagnostic instruments $(\mathrm{N}=10$; studies like Lowe et al. [28]; Sharda et al. [24]; maenner et al. [30]; Frieden et al. [2]). On the other hand systematic table reported that rest of the studies (67\%) used renowned and popular instruments to diagnosed children's with ASD for estimating prevalence $(\mathrm{N}=17)$. For conducting first phase screening investigators used several standardized instruments, as an example $30 \%$ studies used Autism Diagnostic and Observation Schedule (ADOS) $(\mathrm{N}=8$; studies like Saemundsen et al. [19]; Brugha et al. [10]), 15\% studies used The Autism Diagnostic Interview-Revised (ADI-R) (N=4; studies like Samadi et al. [24]; Baron-Cohen et al. [17]; Oliveira et al. [31]), $12 \%$ studies used Childhood Autism Rating scale (CARS) ( $=3$; Monteil-Nava and Pena, [26]; Oliveira et al. [31]), and 8\% studies used Checklist for Autism in Toddlers (CHAT) $(\mathrm{N}=2$; Baron-Cohen et al. [17]). Rest of the studies used other popular assessment instruments like Modified Checklist for Autism in toddlers (MCHAT), Social Communication Questionnaire (SCQ), Autism Spectrum Screening Questionnaire (ASSQ) [6], Pervasive Developmental Disorder Screening Questionnaire (PDDSQ) [22], and The Diagnostic Interview for Social and Communication Disorder (DISCO).

Present review shows that most of the studies used ADOS as screening instruments for their prevalence estimation. ADOS is a standardized diagnostic instrument that used regularly by majority of research studies over 15 years is based on direct observational scoring. According to California department of Developmental services it is an appropriate diagnostic instrument for best practices. It is easy to administer with little training and less time needed for observation (30-60 minutes). According to the dimension and characteristics of ASD the inter-rater reliability [16] and test-retest reliability (0.73-0.82) is good. Also predictive validity is sufficient with sensitivities ranged from $90 \%-97 \%$ [16]. It is commercially available through Western Psychological services and researchers need five day training. ADI-R is a standardized semi-structure interview based on behavioural characteristics of children's at different age. Mainly parents and caregivers help researchers to identify the characteristics of ASD through these instruments. According to researchers ADOS, ADI-R the best instruments for identification of ASD traits among children's in early years. On the other hand CARS is based on DSM-III TR criteria. Therefore over estimation may be possible with mental retardation.

\section{Gender}

According to present review (Table 2), 63\% prevalence studies ( $\mathrm{N}=17$; studies like Blumberg et al. [4]; Aguilera et al. [27]) reported gender proportion of ASD among identified children's. Rest of the 
studies not mentioned gender ratio in their report $(37 \%, \mathrm{~N}=10)$. The overall male female gander ratio was ranged from 6:1 to 1.8:1 [19]. Most of the studies found male dominance in their study. As an example Kim et al. [6] found 5.1:1 found 5.4:1; Lowe et al. [28] found 5.2:1 ratio in their study successfully. Therefore continuation with history no study found girl dominance in ASD. After a complete review of these studies and giving weighted on each sex ratio with the help of 53183 subjects, an average weighted estimate of $3.77: 1$ found.

Therefore most of the studies show similar kind of results of male dominance. Researchers hypothesised that brain structure and chromosomal affects among boys increases the chance of getting diagnosed with ASD. Researchers also rationalized that the inability of widely used assessment tools that is ADOS, ADI-R may underestimate female [17]. Systematic analysis also shows that children's are as young as the male female difference is more prominent. Younger children's has more male dominance than older. As an example Ping et al. [20] found 4:1 ratio with age limit of 1.5 to 2.5 years old children's, Nygren found 4:1 among 2 years old children's, Samadai et al. [24] found 4:1 among 5 year old children's as well. Interestingly study uses much older people in their study and the ratio of gender difference getting decreased accordingly, as an example Sharda et al. [24] found 2:1 ratio with 4 to 37 years old people, Raz found 4.4:5.6 ratio among 8 to 18 years old teenagers. The rational may behind these male dominance may be female children's are not in the picture due to social stigma, cultural disbeliefs and lack of educational structure and parental concern. In a single Australian study [13] nation wise health records shows that more than $80 \%$ of identified children's of ASD are male.

\section{Prevalence estimations}

Near about all the studies $(97 \%, \mathrm{~N}=26)$ calculate the prevalence rate in their report (excepting Durkin et al. [32] ADDM network study). Also interesting finding is that South Korea had maximum prevalence of 264 per 10,000 school age children's in Asia (Kim et al. [6]). Similarly in Europe continent Netherlands had greater increase of ASD among 4-16 years old children's with 229 per 10,000 (Roelfsema et al. [33]). As America is the pioneer in the field of ASD throughout the years, Blumberg and colleagues (Blumberg et al. [4]) shows that 200 per 10,000 children had ASD in the age group of 4-16. On the other hand in Europe continent country like Portugal and Spain had lower prevalence rate in comparison to other countries with 9.4 per 10,000 (Oliverira et al. [31]) to 12.97 per 10,000 [27] in school going children. Saemundsen et al. [19] assessed 22,229 Iceland children aged between 0 - to 8 -years with the estimation of 120.1 per 10,000. In Asian countries Sun et al. [7] found a rate of 119 per 10,000 children aged between 6to 11-years in Beijing. In India Sharda et al. [24] found a sample of 74 students with a prevalence of 12 per 10,000. The average prevalence of the twenty five studies was 91.92 per 10,000 populations.

Interesting finding is that all the studies found higher prevalence out of USA and UK, involved both urban and rural population (Kim et al. [6]; Roelfsema et al. [33]; Saemundsen et al. [19]). Therefore it is significant that ASD is not only based on urban industrial regions of country but also in rural areas. The trend of increasing prevalence rate is found much higher in developed countries than developing. Which maintain the worldwide trend of ASD prevalence and the researcher may hypothesized that due to improved services and greater awareness of the population these difference was found. Meanwhile these studies were conducted sporadically in worldwide, but year wise estimation shows that the prevalence rate increasing continually. Studies from USA (Blumberg et al. [4]) and UK [17] maintain their previous record of high estimation as found by others studies.

\section{ASD and socio-economic condition}

Table 2 shows that total $22 \%$ studies $(\mathrm{N}=6)$ demonstrate the socio economic background of families of these ASD children's. Meanwhile only $11 \%$ studies found positive association between ASD and parental high socio-economic status and education. Brugha et al. [10] found no association between high parental income and presence of ASD in children's. Similarly Sharda et al. [24] not find any significant relationship between children's ASD outcome and increased parental age, marital relation and per-capita income through an Indian study. Oliveira et al. [31] found no association with increased prevalence of ASD and parental high SES in Portugal. King et al. [29] found that having a male child, or older and educated parents increase the risk of ASD. Meanwhile Roelfsema et al. [33] demonstrate that ASD is more common in high socio-economic families than low respected to higher education and higher income. Durkin and colleagues found that increases of income of parents are positively correlated with increasing rate of ASD [30].

According to Durkin et al. [30] when co-occurring cognitive impairment is missing the evidence of SES gradient was strong among ASD prevalence. King et al. [29] rationalize that, parents with high SES delaying in childbirth and ASD is correlated with socioeconomic ingredient. Individual with high resources can receive early diagnosis. Meanwhile other studies not discussed about the impact of SES on diagnosis of ASD.

\section{Limitation of Studies}

Present systematic review identified several limitations of these studies. This limitation's can help future researchers to execute better responsibility. Methodological limitation was very common issue of these prevalence studies. As $22 \%(\mathrm{~N}=6)$ studies mentioned that their populations were not properly defined or had vast incidence that might influence the prevalence (studies like Ping et al. [20]; Taylor et al. [25]). Sufficient sample size is important for any kind of prevalence estimation and it need to be unbiased and representative. In the same time sampling error, mismatch of samples, small sample size and over estimation or under estimation was found in 35\% (N=9) studies (as an example study of Ping et al. [20]; Idring et al. [21]). Administration and selection of diagnostic instruments is a key concern for researchers. Specifically when number of instruments is available it is difficult to select an appropriate tool to screen children's. Present review shows that $15 \%(\mathrm{~N}=4)$ studies found lack of reliability, validity and culture biasness in their administered screening instruments (studies like Blumberg et al. [4]; Idring et al. [21]; Samadi et al. [24]). Also researchers screen haphazardly with the help of teachers, parents and existing school records $(15 \%, \mathrm{~N}=4)$ which may misguide the diagnoses process (as an example study of Ingrid et al. [21]; Baron-Cohen et al. [17]). A diagnostic criterion is a common issue for over diagnosis and under diagnosis. Present systematic review shows that due to overlapping of diagnostic criteria and misclassification $8 \%(\mathrm{~N}=2)$ studies considered that prevalence estimation was effected. Also statistical analysis may be a issue due to lack of power [10].

Frieden et al. [2] rationalize that they used a great amount of general population to estimate prevalence of ASD, but majority of sites include little data from clinical and service provider's, private and charter schools. Therefore a major portion of children's remained unidentified. Similarly Aguilera et al. [27] describes that due to similar features of ASD many mild cases were included in the sample list which cannot be considered as ASD according to DSM-IV criteria. MonteilNava and Pana [26] find that high functioning ASD were lest from case 
Citation: Adak B, Halder S (2017) Systematic Review on Prevalence for Autism Spectrum Disorder with Respect to Gender and Socio-Economic Status. J Ment Disord Treat 3: 133. doi:10.4172/2471-271X.1000133

ascertainment. School records always not a good choice for prevalence estimation because many remains out of centres or home schooling. Also previous year's records were not available sometimes.

\section{Conclusion and Future Directions}

In determining prevalence and providing unbiased picture of affecting factors of ASD epidemiological studies have great importance in the field research. Considering the difference between methodological surveys researchers believed that surveys can provide consistent results. Present systematic review revealed that the rates of ASD were higher among primary school going children's. These epidemiological methodologies have been great educational significance because of multi-stage case findings. Also these surveys can promote the necessity of investigations of ASD in underdeveloped and developing countries also. This type of surveys is important for bringing awareness among professionals and stake holders about ASD. Their planning and conduct can help in raising the awareness among health professionals and educational authorities about ASD and other severe developmental disorders. Review suggests that in developed country like South Korea had maximum prevalence of 264 per 10,000 school age children in Asia.

Therefore it will not be unruly to say that current estimation is significantly higher than previous records of Asian countries. But there are some questions remain unanswered. One of that is whether this increased prevalence rate is true or the improvements of diagnostic criteria and screening instruments are responsible for these rapid increasing. Present systematic review shows that ASD is more prevalent in males and prevalence rate is higher in developed countries in comparison to developing countries of Asia. Further research is needed for developing country like India. Presently there is no exact data for prevalence of ASD. Also parental high socio-economic condition is associated with increased rate of ASD or not it is mare a chance of further research. Prevalence rate is much higher in urban localities, so there is a need for further population based investigation in rural areas.

\section{Delimitation of the review}

Before concluding, several limitations of this review are worth nothing. First, results were based on limited number of studies (27). Second conclusion based on data collected and reported by the reviewed studies. Thirdly, due to limited numbers of studies choices of screening instruments and association between age groups were not discussed in this review. Thus, generalization of these findings is limited and future studies should carefully consider the results.

\section{References}

1. Centers for Disease Control Autism and Developmental Disabilities Monitoring Network (2009) Prevalence of autism spectrum disorders - Autism and developmental disabilities monitoring network, United States, 2006. Morbidity and Mortality Weekly Report 58: SS-10.

2. Fombonne E (2009) Epidemiology of pervasive developmental disorders. Pediatric Research 65: 591-598.

3. Kanner L (1943) Autistic disturbances of affective contact. Nervous Child 2: 217-250

4. Blumberg JS, Bramlett DM, Kogan DM, Schieve AL, Jones RJ, et al. (2013) Changes in Prevalence of Parent-reported Autism Spectrum Disorder in School-aged U.S. Children: 2007 to 2011-2012. Centre for Disease Control and Prevention.

5. CDC (2014) Autism and Developmental Disabilities Monitoring Network Surveillance Year 2010 Principal Investigators. Prevalence of autism spectrum disorder among children aged 8 years - Autism and Developmental Disabilities Monitoring Network, 11 sites, United States, 2010.
6. Kim YS, Leventhal BL, Koh YJ, Fombonne E, Laska E, et al. (2011) Prevalence of autism spectrum disorders in a total population sample. American Journal of Psychiatry 168: 904-912.

7. Sun X, Allison C, Matthews EF, Zhang Z, Auyeung B, et al. (2015) Exploring the under diagnosis and prevalence of autism spectrum conditions in Beijing. International Society for Autism Research 8: 250-260.

8. Nassar N, Dixon G, Bourke J, Bower C, Glasson E, et al. (2009) Autism spectrum disorders in young children: Effect of changes in diagnostic practices. International Journal of Epidemiology 38: 1245-1254.

9. Elsabbagh M, Gauri D, Koh YJ, Young SK, Kauchali S, et al. (2012) Global prevalence of autism and other pervasive developmental disorders. Autism Research 5: 160-179.

10. Brugha TS, McManus S, Bankart J, Scott F, Purdon S, et al. (2011) Epidemiology of autism spectrum disorders in adults in the community in England. Archives of General Psychiatry 68: 459-465.

11. Atladottir HO, Gyllenberg D, Langridge A, Sandin S, Hansen SN, et al. (2014) The increasing prevalence of reported diagnoses of childhood psychiatric disorders: a descriptive multinational comparison. European Child \& Adolescent Psychiatry.

12. Chakrabarti S, Fombonne E (2005) Pervasive developmental disorders in preschool children: confirmation of high prevalence. Am J Psychiatry 162 1133-1141.

13. Williams K, MacDermott S, Ridley G, Glasson EJ, Wray JA (2008) The prevalence of autism in Australia. Can it be established from existing data? Journal of Paediatrics and Child Health 44: 504-510.

14. American Psychiatric Association (1994) Diagnostic and statistical manual of mental disorders. (4thedn) Washington (DC): APA.

15. American Psychiatric Association (2000) Diagnostic and Statistical Manual of Mental Disorders (DSM-IV-TR). (4thedn) Text Revision. Arlington, VA: American Psychiatric Association.

16. Lord C, Rutter M, DiLavore PC, Risi S (2001) Autism Diagnostic Observation Schedule. Los Angeles: Western Psychological Services.

17. Baron-Cohen S, Scott FJ, Allison C, William SJ, Bolton P, et al. (2009) Prevalence of autism -spectrum conditions: UK school-based population study. Br J Psychiatry, 194, 500-509.

18. Hilton CL, Fitzgerald RT, Jackson KM, Maxim RA, Bosworth CC, et al. (2010) Brief Report: Under-representation of African Americans in autism genetic research: A rationale for inclusion of subjects representing diverse family structures. Journal of Autism and Developmental Disorders 40: 633-639.

19. Saemundsen E, Magnússon P, Georgsdóttir I, Egilsson E., Rafnsson V (2013) Prevalence of autism spectrum disorders in an Icelandic birth cohort. BMJ Open.

20. Ping H, Shan SC, Yu H, Hertz-Picciotto I, Hong LQ, et al. (2014) Prevalence and Early Signs of Autism Spectrum Disorder among 18-36 Month Old Children in Tianjin of China. Biomed Environ Sci.

21. Idring S, Rai D, Dal H, Dalman C, Sturm H, et al. (2012) Autism Spectrum Disorders in the Stockholm Youth Cohort: Design, Prevalence and Validity. PLoS One 7: e41280.

22. Surinkaew D, Lauthrenoo O, Charnsil C, Witoonchart C (2005) Prevalence of Pervasive Developmental Disorders in preschool children in Chiang Mai. Chiang Mai Med Bull 44: 29-34.

23. Roelfsema MT, Hoekstra RA, Allison C, Wheelwright S, Brayne C, et al. (2012) Are autism spectrum conditions more prevalent in an information technology region? A school-based study of three regions in the Netherlands. Journal of Autism and Developmental Disorders 42: 734-739.

24. Sharda V, Subbalakshmi NK, Narayana S, Samal RK (2012) Prevalence of autism autistic features and associated risk factors in subjects attending special Schools in our community. Nitte University Journal of Health Science 2: 24-29.

25. Taylor B, Jick H, MacLaughlin D (2013) Prevalence and incidence rates of autism in the UK: time trend from 2004-2010 in children aged 8 years. BMJ Open.

26. Montiel-Nava C, Pena JA (2008) Epidemiological findings of pervasive developmental disorders in a Venezuelan study. Autism 12: 191-202.

27. Aguilera A, Moreno JF, Rodriguez RI (2007) Prevalence estimates of autism 
Citation: Adak B, Halder S (2017) Systematic Review on Prevalence for Autism Spectrum Disorder with Respect to Gender and Socio-Economic Status. J Ment Disord Treat 3: 133. doi:10.4172/2471-271X.1000133

Page 9 of 9

spectrum disorder in the school population of seville, spain. The British Journal of Developmental Disabilities 53: 97-109.

28. Lowe K, Dudley C, Dutton JD, Zwicker DJ, mcmorris C, et al. (2014) Laying the foundation for policy: measuring local prevalence for autism spectrum disorder. The School of Public Policy.

29. King M, Bearman $P$ (2009) Diagnostic change and the increased prevalence of autism. Int J Epidemiol 38: 1224-1234.

30. Maenner JM, Durkin SM (2010) Trends in the Prevalence of Autism on the Basis of Special Education Data. Pediatrics.

31. Oliverira G, Ataide A, Marques C, Miguel T, Countinho MA, et al. (2007)
Epidemiology of autism spectrum disorder in Portugal: prevalence, clinical characterization, and medical conditions. Developmental Medicine \& Child Neurology 49: 726-733.

32. Durkin SM, Maenner JM, Meaney JF, Levy ES, DiGuiseppi C, et al. (2010) Socioeconomic Inequality in the Prevalence of Autism Spectrum Disorder: Evidence from a U.S. Cross-Sectional Study. PLOS ONE.

33. Roelfsema MT, Hoekstra RA, Allison C, Wheelwright S, Brayne C, et al. (2012) Are autism spectrum conditions more prevalent in an information-technology region? A school-based study of three regions in the Netherlands. Journal of Autism and Developmental Disorders 42: 734-739. 